\title{
Application of Computer Technology in Legal Practice
}

\author{
Yuanyuan $\operatorname{Tan}^{1}$, Ying $\mathrm{Li}^{1}$ \\ ${ }^{1}$ Qinhuangdao Radio \& Television University, Hebei, China, 066000
}

\begin{abstract}
Based on the practice of law, the modern technology of electronic computer means and the practice that can be accepted by everyone who has been processed by electronic means have been obtained by the scientific and technological means that are now widely popular in the education field. Since its inception, in education A huge butterfly effect has been produced in the world, which has changed the thoughts, means and methods inherent in human practice in the past, making the practice of law more convenient, faster, visualized and foreseeable. The purpose of this article is to study the application of computer technology in legal practice. This article uses literature method, questionnaire survey method, expert interview method, field investigation method and other research methods, taking the application research of computer technology in the practice of law science as the research object, and conducts research on the application status and main problems of law practice courses in a university in this province. According to the survey and analysis, $28 \%$ of the students believe that their practical ability has been significantly improved after legal practice based on computer technology, master basic legal theory knowledge, and train themselves to use legal theory to analyze and solve individual legal cases. Ability, $42 \%$ of students believe that their transaction processing ability has improved to a certain extent compared to before.
\end{abstract}

\section{Introduction}

The application of computer technology in legal practice has improved work efficiency to a certain extent. The application of computer technology in legal practice is based on the collection and sorting of case information based on computer systems and citizen information databases, and the information is analyzed by query analysis and data analysis. The system conducts a comprehensive inspection and integration to improve the accuracy and systemicity of learning practice [1-2].

There are earlier online computer-assisted teaching applications abroad. The United States has produced computer-assisted online teaching in the 1950s, the PLATO system was produced in the $1960 \mathrm{~s}$, and the Stanford University in the United States subsequently developed the IBM1500 new teaching system. In the 1990s, the Massachusetts Institute of Technology developed ATHEAN. Computer-assisted online teaching appears in the Internet era [3-4]. So far, Internet-based teaching systems have sprung up. Online assisted teaching in the United States and European countries has been industrialized. One of the more successful companies is PERSON ECOLLEGE in the United States. The company is a world-leading, well-known enterprise that successfully integrates education and technology with outstanding results. It provides a personalized teaching and learning environment, creating a globally scalable, advanced, reliable and safe SAAS learning system [5-6]. It also fully analyzes the student characteristics of the application of the Internet-assisted learning system. The domestic computer-assisted legal practice has not yet formed a complete system, and the research on the strategies and methods of the use of legal resources on the computer platform is relatively rudimentary [7-8].

From the perspective of the integration of computer multimedia technology and legal practice theory, this article explores new methods and models of computerassisted legal practice, and constructs a multi-structured teaching model based on computer-assisted legal practice [9-10]. Through the research around the computer digital network learning platform technology, summarize the computer-assisted legal practice theory and teaching methods, explain the basic functions and teaching methods of the digital network learning platform legal practice, and propose a legal education form based on the computer digital network learning platform [11-12].

\section{Application of Computer Technology in Legal Practice}

\subsection{Analysis of the Application Advantages of Computer Technology in Legal Practice}

(1) Improve the accuracy of legal practice After the application of computer technology is practiced in law, the computer will work according to the established principles of the program. In the entire process of processing information and data, due to personal subjectivity, it will be different from traditional legal 
practices, and the direction of legal practice will be different. The computer system can manage and supervise the entire legal practice project in accordance with the established procedural principles. At the same time, the computer system has high speed and accuracy in information and data analysis, which can free relevant personnel from performing complex and tedious analysis of information and data, reduce personnel costs, and enable relevant personnel to make better practical investments. In terms of legal management, the accuracy of legal practice has been effectively improved.

(2) Standard management

The review based on the traditional case law model is very difficult, and as time goes by, more and more case law document, chapters and documents will be brought. This also makes data management and access more difficult. At the same time, in document management, legal practice materials are easily destroyed and lost. With the application of computer technology in legal practice, the use of information management and retrieval methods can significantly improve efficiency and reduce unnecessary losses. After applying computer technology to legal practice, the control task is also very convenient, and the specific location to be analyzed can be quickly found through the computer. The results of legal practice can also be classified and stored. No matter how the time changes, the computer system can intuitively request the legal practice at a specific time in the information database.

(3) Further improve data transparency

The application of computer technology in legal practice has further enriched legal practice. The results of legal practice are published on related websites, which can facilitate people's search and consultation. Each unit can rely on the computer network to exchange information and data, thereby promoting the development, unity and cooperation of my country's legal practice units.

(4) Guarantee the effectiveness of the results of legal practice

Regarding the results of legal practice, it is usually necessary to maintain a large amount of printed information under the influence of traditional transition methods. The printed information is not only difficult to maintain, but also easy to lose or leak related information and data. Applying computer technology to legal practice can alleviate such problems to a certain extent, reduce written information, and protect information through an encrypted emergency computer database, so as to make the results of legal practice more convincing and better protect the legal practice.

\subsection{Application Principles of Computer Technology in Legal Practice}

A good lesson is like building a bridge, which requires meticulous design and planning before construction. Poor design will cause the bridge to be weak and unable to function as a load-bearing or pivotal bridge. A good teaching design is the basic technical support for a good lesson, and a solid "bridge" for teachers to pass knowledge to students. To add the application of computer technology to legal practice, we must first follow the teaching connotation, basic theory and general characteristics of the practical course. To follow the following basic principles:

(1) Systematic principle

When carrying out the application of computer technology in legal practice, it is necessary to dialectically unify, internalize the parts into the whole, and make the whole coordinate between the parts. The teachers, teaching objects, teaching resources, and teaching activities involved in the practical courses are required to coordinate and cooperate with each other, and do not ignore one or the other, and design a practical classroom with systematic principles as the center of presenting the best teaching effect, and realize the teaching design optimize.

(2) The principle of openness

Regardless of textbooks and traditional knowledge, relevant knowledge can be appropriately expanded on the basis of the necessary knowledge, broaden students' thinking and horizons, and exercise students' spirit of thinking, thinking, and inquiring more.

(3) Interaction principle

The practice of law based on computer technology is contrary to the traditional classroom. The class should give more opportunities for discussion, debate, and research between students and teachers. Therefore, in the application of computer technology in legal practice, we must follow the principle of interaction, and give teachers and students sufficient time for interaction in teaching activities.

(4) The principle of feedback

Law practice should include timely feedback of teaching effects. Through feedback, it can be used to test which part of the teacher's teaching is highly efficient and which part of the teaching is problematic, which can provide reference and reference for subsequent teaching design. It is still necessary to track and monitor students' learning effects after class, which can improve the quality of teaching reflection and optimize the content of flipped classroom teaching design.

(5) The principle of feasibility

Legal practice should be designed according to the actual conditions of the teaching objects, course objectives, and learning environment, to maximize the role of various teaching resources, adapt to local conditions, and tailor the law to give new vitality to legal practice, and promote the application of computer technology in legal practice.

\subsection{Focus of the Application of Computer Technology in Legal Practice}

(1) Computer software in legal practice

The application of computer technology in legal practice must be based on stable and good computer operating software. Therefore, all units must adopt national comprehensive legal practice software and ensure compatibility with their respective systems to ensure the smooth operation of software and information, and the stability of data entry and management.

(2) Operation of software for legal practitioners

The application of computer technology in legal practice requires relevant personnel to be able to operate 
computer software. The main actions of legal practitioners will shift from pure data processing to the process of improving computer software operating capabilities to ensure that the application of computer technology in legal practice plays a key role in related work.

(3) Effectively analyze computer information data

Analyze information and data through computers, discover problems in computer systems and determine the focus of legal practice. In actual work, legal practitioners should always make full use of the functions of legal practice software, conduct a comprehensive analysis and prediction of information and data, determine the problematic part, and make it the focus of the next legal practice step.

\subsection{The teaching method of the application of computer technology in legal practice}

(1) Multimedia conventional teaching

Multimedia conventional teaching includes PPT, Word, Excel, etc. It is a computer-assisted conventional teaching method. Its characteristic is that it does not require network support. It only needs a computer and a projector to complete the teaching method. It is also the most common teaching method at present. This type of multimedia conventional teaching is mainly used by teachers to integrate media materials into courseware, which can be used repeatedly, but it has shortcomings such as untimely update of resources and boring informationbased teaching classrooms. It is similar to "cracking duck" teaching, students are less involved in the teaching process.

(2) Network teaching based on computer support

Computer-based legal practice teaching is a new generation of teaching technology with the Internet as the main body, so network-supported teaching is the main method of modern information teaching. Computersupported network teaching includes MOOC, Internet teaching platform, and excellent law courses.

\section{Application Research Experiment of Computer Technology in Legal Practice}

\subsection{Research Objects}

In the research process, this article uses typical sampling to select four universities in the province, and takes random samples to conduct questionnaire surveys.

\subsection{Statistical Analysis}

Use Excel software to sort out the recovered valid questionnaires, and use SPSS21.0 to statistically analyze the data obtained from the application of computer technology in the legal practice of universities in the province. This article conducts a T-test on the reliability of the questionnaire and the T-test formula used as follows:

$$
\begin{aligned}
& t=\frac{\bar{X}-\mu}{\frac{\sigma X}{\sqrt{n}}} \\
& t=\frac{\overline{X_{1}}-\overline{X_{2}}}{\sqrt{\frac{\left(n_{1}-1\right) S_{1}^{2}+\left(n_{2}-1\right) S_{2}^{2}}{n_{1}+n_{2}-2}\left(\frac{1}{n_{1}}+\frac{1}{n_{2}}\right)}} \\
& t=\frac{\bar{d}-\mu_{0}}{s_{d} / \sqrt{n}}
\end{aligned}
$$

\section{Experimental Analysis on the Application of Computer Technology in Legal Practice}

\subsection{Student Recognition of the Curriculum Model of the Application of Computer Technology in Legal Practice}

After the completion of the legal practice based on computer technology, a survey of students' preference for practical courses was conducted. The survey results are shown in Table 1.

Table 1: Survey of students' preference for flipped classroom

\begin{tabular}{|c|c|c|}
\hline & $\begin{array}{c}\text { Number of } \\
\text { people }\end{array}$ & Proportion \\
\hline Like Very Much & 22 & $22 \%$ \\
\hline Like & 57 & $57 \%$ \\
\hline General & 19 & $19 \%$ \\
\hline Dislike & 2 & $2 \%$ \\
\hline
\end{tabular}




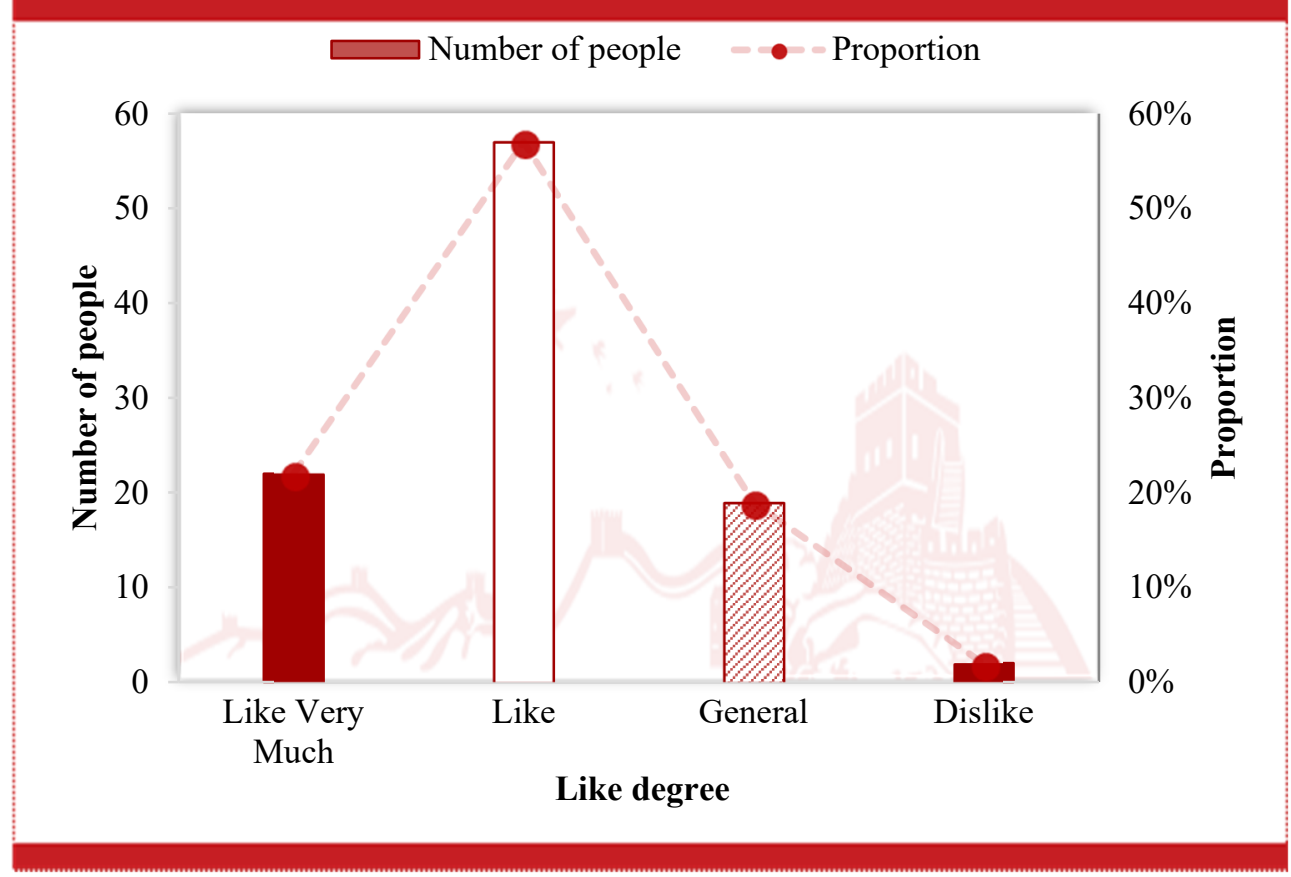

Figure 1: Survey on the degree to which students like the flipped classroom

It can be seen from the Figure 1: $22 \%$ of students like the law practice classroom based on computer technology very much, $57 \%$ of the students like it, and a very small number of students do not accept this teaching mode. After sorting out the survey data, it is found that most students like law practice, and students believe that this teaching mode can help their study. The above can fully prove that the legal practice based on computer technology is still highly recognized among students, that is, the legal practice based on computer technology is feasible.

\subsection{Results of the Evaluation of the Improvement of Students' Ability}

Legal practice based on computer technology focuses on the cultivation of students' application ability, which includes oral and expression skills. Aiming at the cultivation of these two abilities, the students who participated in the legal practice class based on computer technology were tested on the effect of ability improvement. The evaluation results are shown in Table 2 .

Table 2: Survey results of students' oral and expression ability in flipped classroom

\begin{tabular}{|c|c|c|}
\hline & Speaking Ability & $\begin{array}{c}\text { Expression } \\
\text { Ability }\end{array}$ \\
\hline $\begin{array}{c}\text { Significantly } \\
\text { improved }\end{array}$ & $28 \%$ & $24 \%$ \\
\hline Slightly improved & $42 \%$ & $48 \%$ \\
\hline Not clear & $28 \%$ & $19 \%$ \\
\hline No improvement & $2 \%$ & $9 \%$ \\
\hline
\end{tabular}

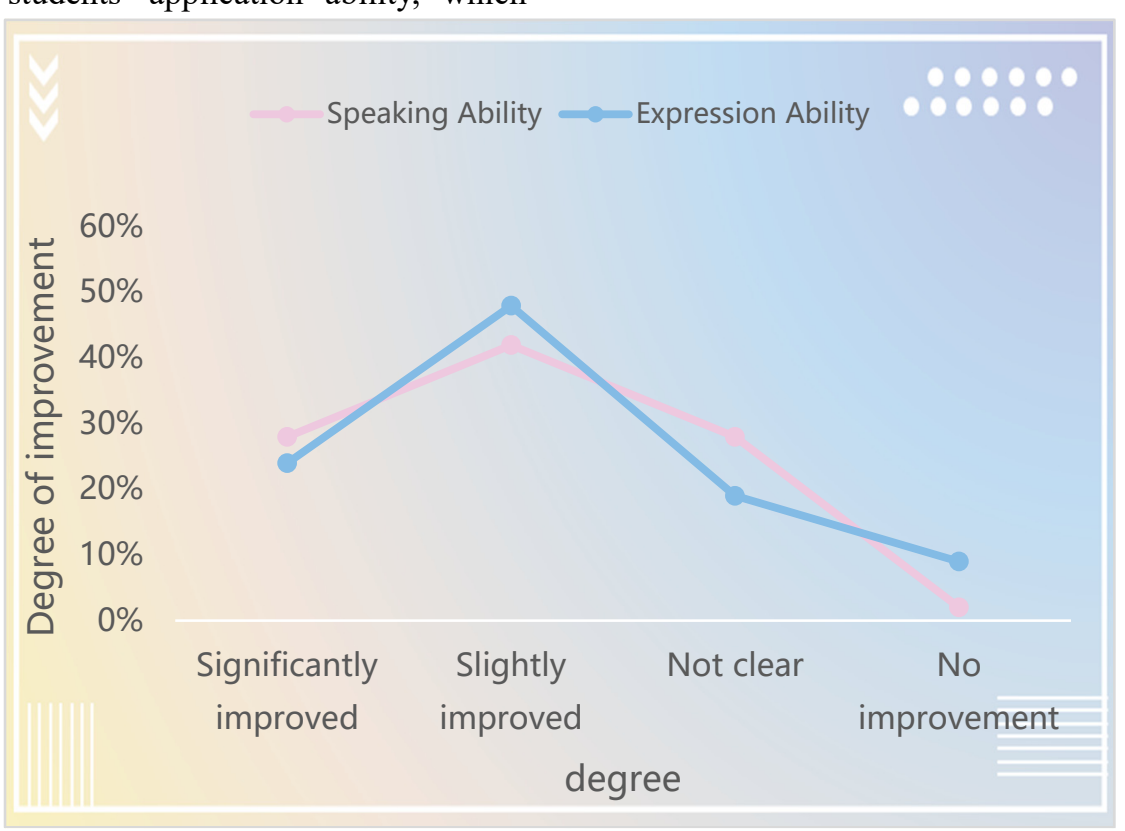

Figure 2: Survey results of students' oral and expression ability in flipped classroom 
$28 \%$ of the students believe that their practical ability has been significantly improved after legal practice based on computer technology, mastering basic legal theory knowledge, and training themselves to form the ability to use legal theory to analyze and solve individual legal cases, $42 \%$ The students think that their ability to handle affairs has improved to a certain extent compared to before. However, $28 \%$ of the students did not know whether their ability to solve legal cases has improved. This survey result reflects that the legal practice based on computer technology not only helps students master the basic theoretical knowledge of law, but also helps students form specific abilities to apply law in practice.

\section{Conclusions}

This article starts from the perspective of the integration of computer technology and research learning, and based on the application research of computer technology in legal practice, to explore the legal practice teaching mode based on the computer technology environment. According to the main ideas expounded in this article, the research questions in the process of constructing the practice model of computer-assisted law. With the vigorous development of digital information technology and Internet science and technology, research-based learning based on computer-assisted legal practice has gradually become the preferred learning method for law education in colleges and universities, and it is also a powerful learning method for lifelong education. This article does some preliminary research on the research learning in the context of digital network under the background of the rapid development of contemporary science and technology, and hopes that the theory of research and discussion can give a little bit of enlightenment to modern legal education.

\section{References}

1. Ponomareva K A. Business splitting: compliance with the principle of tax certainty in law enforcement practice[J]. Law Enforcement Review, 2020, 4(2):4148.

2. Hulsen L T, Mard S. Coding and Conceptualizing Technology in the Future of Law and Legal Practice: An Overview of the ALF Annual Seminar 2019[J]. Amsterdam Law Forum, 2019, 11(3):76.

3. Yang J, Ma Y, Mao M, et al. Application of regression model combined with computer technology in the construction of early warning model of sepsis infection in children[J]. Journal of Infection and Public Health, 2020, 13(2):253-259.

4. Wang Q, Lu P. Research on Application of Artificial Intelligence in Computer Network Technology[J]. International Journal of Pattern Recognition and Artificial Intelligence, 2019, 33(5):1959015.11959015.12.

5. Lan L, He Y, An J, et al. Application of ComputerAided Navigation Technology in the Extraction of
Foreign Body From the Face[J]. Journal of Craniofacial Surgery, 2019, 31(2):1.

6. Wang P, Feng X. Research on the Application of Computer Technology in the Dissemination and Promotion of Folk Art Culture[J]. Journal of Physics: Conference Series, 2021, 1744(3):032197 (3pp).

7. Prelevi-Paladino A. A critique of the jusnaturalist notion of marriage: A view from Italian legal practice $[\mathrm{J}]$. Glasnik Advokatske komore Vojvodine, 2020, 92(4):676-725.

8. Solodun Y V, Zlobina O Y, TM Piskareva, et al. POSTTRAUMATIC PSYCHOPATHOLOGICAL MANIFESTATIONS OF THE HEAD INJURY IN MEDICO-LEGAL PRACTICE[J]. Russian Journal of Forensic Medicine, 2020, 5(4):28-33.

9. Zaprutin D G, Nikiporets-Takigawa G, VV Goncharov, et al. LEGAL PRACTICE IN THE BLOCKCHAIN ERA: THE USE OF ELECTRONIC EVIDENCE[J]. Revista de Gênero Sexualidade e Direito, 2020(5):404-418.

10. Bleasdale L, Francis A. Great expectations: millennial lawyers and the structures of contemporary legal practice[J]. Legal Studies, 2020, 40(3):1-21.

11. Simonova $\mathrm{S}$ V. Ensuring the Reliability of Information on the Internet: Modern Legal Framework and Legal Practice[J]. Actual Problems of Russian Law, 2020, 15(11):172-179.

12. Lynch H F, Greiner D J, Cohen I G. Overcoming obstacles to experiments in legal practice[J]. Science, 2020, 367(6482):1078-1080. 